\title{
Sobre a experiência sexual dos jovens
}

\author{
Young people's sexual experience
}

\author{
1 Escola Paulista de \\ Medicina, Universidade \\ Federal de São Paulo, \\ São Paulo, Brasil. \\ 2 Faculdade de Medicina \\ de Ribeirão Preto, \\ Universidade de São Paulo, \\ Ribeirão Preto, Brasil. \\ Correspondência \\ W. V. Villela \\ Departamento de Medicina \\ Preventiva, Escola Paulista \\ de Medicina, Universidade \\ Federal de São Paulo. \\ Rua Borges Lagoa 1341, \\ São Paulo, SP \\ 04038-034, Brasil. \\ wilsa.vieira@terra.com.br
}

\section{Abstract}

The rise in teenage pregnancy and young people's vulnerability to HIV have been a serious problem. This paper is intended to confront this statement based on its structural concepts (adolescence, youth, teenage pregnancy, and vulnerability) and by a non-exhaustive review of the relevant literature. The current paper discusses the ideas of youth and adolescence to approach the sexuality of young people and adolescents from the perspective of inequalities between different social groups and their access to health and resources for the prevention of diseases like HIVIAIDS as well as contraception. There are multiple paths leading young people to having unprotected sexual relations, and the numbers that surface on pregnancy, STDs, and HIV infection are doubtless lower than the real figures. The data presented herein indicate that the safesex approach is still necessary among youth, requiring efforts to produce creative strategies that make sense in different socio-cultural contexts in which young people experience sex.

Pregnancy in Adolescence; HIV; Adolescent; Public Policies
Wilza Vieira Villela 1

Daniella Tech Doreto 2

\section{Introdução}

Adolescente e jovem são categorias constituídas por meninos e meninas que trazem experiências, práticas sociais e estilos de vida distintos, em função das atribuições de gênero, suas complexas articulações com classe social e raça/etnia e as marcas que estas pertenças imprimem à subjetividade de cada um.

Assim, pensar a gravidez na adolescência ou a vulnerabilidade dos jovens ao HIV exige a reflexão sobre os diversos sentidos que o exercício da sexualidade adquire para cada uma dessas pessoas que, talvez, só tenham em comum o fato de terem nascido num mesmo período de tempo.

No contexto de homogeneização de comportamentos e estilos de vida que caracteriza a sociedade contemporânea, ser "jovem” significa mais do que uma delimitação etária: ser jovem é ser novo e inovador, projetado para o futuro; juventude é beleza, leveza, humor, responsabilidade, coragem, ousadia e... sexo.

No entanto, nem todos os jovens se expõem igualmente a essa concepção de juventude, pois as informações se difundem de modo distinto pelas camadas sociais e são elaboradas contextualmente, fazendo com que a idéia de juventude, do que é adequado ou não a esse período, ou mesmo a sua duração, seja vivenciada de maneira particular nos diversos grupos. 


\section{Juventude e adolescência}

A idéia de que entre a infância e a fase adulta existe um período intermediário, com características próprias, é recente. Sua emergência está relacionada às transformações ocorridas no último século e seus impactos na organização do trabalho e nos comportamentos reprodutivos.

O crescimento da indústria nos séculos XIX e XX amplia a gama de habilidades necessárias para a ocupação dos novos postos de trabalho que surgem, exigindo maior preparo do trabalhador. A extensão do tempo de formação profissional posterga a entrada no mercado, o que leva também a um adiamento do início da vida reprodutiva, para homens e mulheres.

Trabalho e reprodução são marcadores do que se costuma chamar de "vida adulta". Seu início mais tardio produz um hiato entre esta fase e a infância. É a partir desse hiato que nascem as idéias de "juventude", e, posteriormente de "adolescência", entendidas como períodos de aprendizagem e preparação para o futuro.

Sendo a juventude e a adolescência instituídas por referência à entrada no mundo do trabalho, os limites que definem seu início e seu final são imprecisos e variáveis, e fortemente marcados pela inserção social do indivíduo.

Ao mesmo tempo, a reprodução, pensada no contexto do casamento, exige do varão a capacidade de prover a família. Isso cria um entrelaçamento entre trabalho e reprodução, com base em uma divisão de papéis entre homens e mulheres, que não inclui a idéia de sexualidade e rejeita a possibilidade de reprodução fora de um vínculo conjugal.

\section{Ser jovem ou ser adolescente?}

A adolescência e a juventude se distinguem por recortes etários: adolescentes seriam pessoas entre 10 a 20 anos, enquanto os jovens teriam entre 15 e 24 anos 1 . Há, pois, uma importante interseção entre os dois grupos.

Kraiczyk 2 sugere que a diferença entre juventude e adolescência repousaria na gama de sentidos atribuídos a cada um dos termos: adolescência traria o sentido etário, enquanto a juventude traria um sentido geracional. Para Waiselfilsh 3 , juventude tem um sentido coletivo que remete a um segmento populacional de uma sociedade, ao passo que a adolescência está mais relacionada ao plano individual, demarcado cronologicamente.

Os significados relacionados à idéia de adolescência têm, em geral, um caráter negativo, remetendo à dependência, irresponsabilidade, dificuldades emocionais e impulsividade, enquanto os de jovem são altamente positivados, remetendo à independência, criatividade e responsabilidade. Um jovem não necessariamente se vê ou é visto como adolescente ou como pouco responsável pelo fato de ter menos de vinte anos.

Desse modo, para analisar a atividade sexual dos jovens, é importante considerar como cada um se situa em relação a si mesmo e à sua capacidade de responder pelos seus atos, tendo por referência os diferentes sentidos sociais atribuídos à adolescência e à juventude.

\section{A sexualidade dos jovens}

Se hoje uma jovem inicia sua carreira reprodutiva entre 15 e 20 anos, como suas avós e bisavós, há o sentimento que está deixando de aproveitar as oportunidades que o mundo lhe oferece, em especial em termos de escolarização e trabalho. O mesmo ocorre em relação aos rapazes que, frente a uma gravidez da parceira, devem parar de estudar para trabalhar e sustentar a família. Em alguns casos as trajetórias se constroem exatamente com foi descrito, mas essa não é uma regra. Nem todos os jovens interrompem definitivamente a sua formação profissional pelo fato de terem filhos, nem todos os jovens que têm filhos tinham interesse, capacidade e chance de maior de escolarização e inserção qualificada no mercado de trabalho. O mesmo pode ser dito em relação à infecção pelo HIV que, embora cada vez mais se transforme em uma doença crônica com a qual é possível (com)viver, ainda é entendida por muitos como uma sentença de morte.

O risco de gravidez ou de infecção pelo HIV entre jovens deve ser considerado em termos das suas possibilidades reais, mas também em relação aos discursos que se elaboram em torno do exercício da sua sexualidade.

Desde a era cristã a sexualidade é tida como algo potencialmente perigoso que, portanto, exige controle e traz castigos para quem infringe suas regras, o que contrasta e complementa a idéia de "descontrole" ou "rompimento de limites", relacionada à adolescência e à juventude, fazendo com que a prática do sexo pelos jovens seja vista como um receio.

A epidemia pelo HIV é uma ameaça real, e não apenas para os jovens. As gestações não planejadas também, em qualquer idade. Assim, são necessárias políticas públicas de saúde e de educação que minimizem os riscos relacionados ao exercício da sexualidade pelas pessoas em qualquer idade. 


\section{Quem são os jovens, os adolescentes e os adolescentes jovens no Brasil?}

O grupo de 10 a 20 anos representa hoje aproximadamente $21 \%$ da população do Brasil. Existe um relativo equilíbrio entre os sexos e entre as raças 4, que não ocorre em relação à classe social: apenas $20 \%$ dos adolescentes brasileiros pertencem às categorias A e B e $50 \%$ dos jovens de 15 a 20 anos são pobres ou extremamente pobres 5 . A população entre 15 e 20 anos atinge, em média, entre 6 e 8 anos de estudo, havendo importantes diferenças regionais e entre brancos e negros. A taxa de analfabetismo entre jovens negros é o dobro da dos brancos, e quatro vezes maior quando se considera a faixa etária de 10 a 14 anos 6 .

Aproximadamente três quartos dos jovens de renda mais baixa ingressam no mercado de trabalho antes dos 15 anos, com média salarial inferior à do conjunto dos trabalhadores. Entre as camadas mais pobres, $23 \%$ dos jovens conseguem trabalhar e estudar, mas $17,1 \%$ não trabalham nem estudam. Entre as meninas o percentual de não trabalho e não estudo chega a $26 \% 5$.

\section{A vulnerabilidade dos jovens}

Vulnerabilidade pode ser vista como o produto da interação entre características do indivíduo - cognição, afeto, psiquismo - e estruturas sociais de desigualdade - gênero, classe e raça determinando acessos, oportunidades e produzindo sentidos para o sujeito sobre ele mesmo e o mundo.

Uma pessoa pode tornar-se menos vulnerável se for capaz de reinterpretar criticamente mensagens sociais que a colocam em situações de desvantagem ou desproteção, mas a sua vulnerabilidade pode aumentar se a mesma não tem oportunidades de ressignificar as mensagens emitidas no seu entorno.

Nas sociedades contemporâneas a escola tem sido o espaço privilegiado para a aquisição de habilidades cognitivas e sociais por crianças e jovens, facilitando os processos de recriação de si e do mundo e, assim, reduzindo a sua vulnerabilidade social. Jovens fora da escola têm menos chances de reinterpretar as mensagens pejorativas relacionadas às idéias de pobreza, negritude e feminilidade, o que interfere no modo como será exercida a sua sexualidade.

\section{A gravidez entre os jovens}

A forte significação positiva da maternidade pode ser entendida como uma contraface de desqualificação social das mulheres. No caso de meninas pobres esta importância simbólica pode tornar-se ainda maior pela dificuldade de acesso a outros bens sociais, como educação, trabalho, remuneração e prestígio 7 .

Segundo a Organização das Nações Unidas para a Educação, a Ciência e a Cultura (UNESCO) $8,32,8 \%$ dos jovens brasileiros entre 12 e 17 anos já iniciaram a sua vida sexual, sendo que destes, $61 \%$ são rapazes e $39 \%$ são moças. Quanto menor a escolaridade, mais cedo começa a vida sexual. A gravidez logo após o início da vida sexual é freqüente $8,9,10$.

A dinâmica das relações de gênero impõe às moças o recato em relação ao sexo, enquanto que, para os rapazes, é esperado que não haja muito pudor ou embaraço em relação ao tema. Isso resulta no elevado valor atribuído à virgindade, para as moças, e à experiência sexual, para os rapazes. Tal descompasso de expectativas nem sempre corresponde às vivências individuais, mas dificulta o diálogo aberto sobre sexo e o compartilhamento de estratégias para que o início da vida sexual não traga surpresas desagradáveis.

Os coeficientes de fecundidade de jovens de uma mesma faixa etária são distintos em função da sua inserção social. Em 1996, por exemplo, as adolescentes mais pobres apresentavam uma fecundidade de 128 por mil mulheres, enquanto que para as mais ricas este coeficiente era de 13 por mil mulheres 6 . Ou seja, jovens com mais renda, que dispõem de um leque maior de oportunidades na vida para além da maternidade, tendem a postergar o início da vida reprodutiva e têm mais acesso aos meios contraceptivos. Além disso, se for necessário, é possível interromper uma eventual gravidez com segurança.

A escolaridade também interfere na fecundidade: quanto mais escolarizada, menor é a fecundidade da jovem. Isso sugere que, para algumas jovens, pobres e pouco escolarizadas, convivendo com apelos de consumo e percebendo-se apartadas das possibilidades de um dia vir a acedê-los, talvez a gravidez não seja um problema, e sim uma solução, um meio de aquisição de identidade e função social. O problema passa a existir na medida em que não existem ações que quebrem o círculo vicioso entre pobreza e exclusão para essas jovens e seus filhos.

A maior incidência de gravidez entre jovens pobres e de menor escolaridade sugere a difi- 
culdade de acesso a informações sobre contracepção e aos insumos contraceptivos. No entanto, o conhecimento sobre métodos contraceptivos não garante seu uso. Estudo conduzido em Ribeirão Preto, São Paulo, Brasil, com 100 puérperas adolescentes mostrou que $79 \%$ conheciam um número de métodos anticoncepcionais entre alto ou regular e $76 \%$ tinham um bom conhecimento sobre os atributos dos contraceptivos 11. Pesquisa realizada em São Paulo em 2004 mostra que embora $87 \%$ dos jovens tenham declarado conhecer os métodos contraceptivos, $70 \%$ tiveram a primeira relação sexual sem nenhuma proteção 12, o que pode ser resultado de um modelo de socialização que recusam às mulheres o exercício da sexualidade, fazendo com que as meninas não desenvolvam habilidades para falar de sexo e sintam-se pouco à vontade para abordar o tema com o parceiro.

Estudo realizado em três capitais brasileiras, com cerca de 2.600 mulheres jovens 10, mostra que entre as que conversaram com os parceiros sobre contracepção houve maior taxa de uso de contraceptivos na primeira relação e menor taxa de gravidez. Do mesmo modo, aquelas cujas mães e os pais conversaram sobre sexo, gravidez e modos de evitar filhos, ou que tiveram alguma orientação sexual na escola engravidaram menos. A mesma pesquisa mostra que não ocorreu gravidez entre as jovens que só "ficavam" [forma de experimentação sexual onde não há compromisso, podendo ou não haver uma relação sexual completa] e que a taxa de gravidez entre as meninas que ficavam e namoravam foi menor do que entre as que só namoravam, evidenciando que, para as meninas, a experimentação sexual facilita a autonomia.

É necessário lembrar que as jovens dispõem de um leque restrito de opções contraceptivas: a pílula, que pode ser comprada livremente nas farmácias, desde que haja recursos para isso, ou pode ser obtida em unidades de saúde, se houver um médico que a prescreva, o que nem sempre ocorre, pois muitos relutam em prescrever pílulas para jovens, e o preservativo, cujo uso depende da vontade do parceiro. O uso deste método tem crescido nos últimos anos, segundo o Ministério da Saúde 13, principalmente por rapazes, que o usam quase que duas vezes mais que as moças ( $65 \%$ vs. $35 \%)$. No entanto, entre os moços que nunca usaram preservativos, $83 \%$ pertencem às classes $\mathrm{C} \mathrm{e} \mathrm{D}$.

O impacto da gravidez na vida dos jovens é polêmico. Segundo a UNESCO 8, meninas escolarizadas acreditam que a gravidez nessa fase leva a jovem a abandonar a escola, pelo preconceito que ali sofre e pela necessidade de cuidar do bebê, que atrapalha o estudo. No en- tanto, de acordo com Aquino et al. 10, 42,1\% já se encontravam fora da escola, $25 \%$ interromperam os estudos mas depois retomaram, e apenas $17,3 \%$ pararam de estudar definitivamente. Vale ressaltar que $79,8 \%$ das jovens que experimentaram a maternidade antes dos 20 anos viveram esta experiência a partir de um relacionamento estável, ou seja, estavam ou sentiam-se casadas 13 .

Muitas jovens iniciam-se sexualmente e engravidam de parceiros também jovens. Paiva et al. (1998, apud Oliveira-Costa 14), por exemplo, cita uma proporção de $70 \%$ de pais jovens, dos quais $85 \%$ se mantêm na relação após o nascimento da criança. Takiuti 15, entrevistando parceiros de mães adolescentes, encontra que $38,7 \%$ também são adolescentes.

Outro estudo, realizado em Feira de Santana com 438 mães entre 10 e 19 anos, 14 mostra que $32,6 \%$ coabitavam com o pai da criança e $34,5 \%$ dos parceiros também tinham menos de 19 anos; entre as jovens, $85 \%$ eram analfabetas ou tinham apenas o ensino fundamental e $60 \%$ dos rapazes tinham concluído ou estavam cursando o ensino fundamental; $54,7 \%$ dos parceiros não trabalhavam ou auferiam renda inferior a um salário mínimo. Ou seja, os jovens pais também se encontram em uma situação de grande vulnerabilidade social. No entanto, pode-se supor que para muitos rapazes a paternidade e o trabalho necessário ao sustento da prole significam a sua identificação com o grupo de "trabalhadores" e "pais", e não o de “jovens". Ser pai é tornar-se "homem", podendo significar uma contraface compensatória da impossibilidade de ser "jovem".

Pesquisa realizada com rapazes de 15 a 19 anos no Rio de Janeiro, 16 evidencia a pluralidade de circunstâncias e sentidos que circundam a entrada na vida reprodutiva antes dos 20 anos: gravidez planejada, amor entre os parceiros, antídoto à anomia, autoproteção contra a sedução do tráfico e do crime e outras, sugerindo que a gravidez de jovens é um fenômeno heterogêneo, cujo entendimento e abordagem exigem contextualizações mais específicas, incluindo a discussão sobre a paternidade jovem.

Para terminar esta seção são necessárias ainda algumas considerações sobre o aborto. $\mathrm{O}$ número de internações por aborto incompleto entre meninas de 10 a 19 anos vem aumentando nos últimos cinco anos, tendo sido registrados 181 óbitos por esta causa entre meninas de 10 a 20 anos de 1998 a 2003 17. Ressalte-se também que quase $50 \%$ das meninas que recorrem a aborto não punível têm menos de 20 anos, apontando a conexão entre gravidez na adolescência e abuso sexual, e, possivelmente, entre 
o trabalho sexual de menores e a gravidez na adolescência.

\section{DST/HIV/AIDS entre jovens}

O Brasil tem um programa de AIDS considerado exitoso, em função da política de acesso universal aos medicamentos anti-retrovirais, e da parceria com a sociedade civil para o desenvolvimento de ações para diferentes públicos alvos. Apesar de haver algum tipo de atividade de prevenção do HIV em $70 \%$ das escolas do país, nos últimos anos houve uma redução do nível de conhecimento sobre Aids entre a população de 15 a 24 anos, maior entre os grupos de menor escolaridade 18 . O uso do preservativo na primeira relação sexual foi referido por $49 \%$ dos jovens entre 15 e 24 anos, e seu uso entre rapazes de 17 a 21 anos das classes A e B atinge $57 \%$ em relações eventuais. Este perfil reitera a relação entre desigualdade social e desigualdade de acesso às práticas de prevenção sexual, relação que deve ser interpretada também em função do universo de valores e sentidos relacionados ao sexo que informam o cotidiano destes.

Jovens de classes sociais mais favorecidas postergam o início de sua vida sexual e usam mais proteção porque têm acesso à informação e aos insumos, e também porque sentem que suas vidas têm valor, têm projetos para o futuro e existem outros suportes para ancoragem da auto-estima que não apenas a realização sexual/amorosa.

Usar o preservativo não é fácil. Encontros sexuais muitas vezes ocorrem entre pessoas que mantêm entre si uma relação erótica, mas também uma relação de poder mediada pelo gênero, pela classe social ou pela diferença de idade. Quem detém o poder tem mais chance de "garantir" o uso do preservativo, como também de não aceitar seu uso.

Outra importante estratégia de prevenção do HIV é a testagem, pois o aconselhamento pré e pós-teste reforçam as condutas preventivas, e para aqueles que se descobrem portadores do vírus pode-se iniciar tratamento e enfatizar ainda mais as práticas de prevenção. No entanto, entre as pessoas de extratos sociais mais baixos, a cobertura da testagem anti-HIV atinge um porcentual de apenas $25 \%$, sendo que parte importante deste porcentual relaciona-se à realização de pré-natal 19.

No Município de São Paulo 20, em 2004, ocorreram 23 gestações em menores de 20 anos, portadoras do HIV, que se infectaram por transmissão vertical, ou seja, nasceram com HIV e tiveram contato continuado com serviços de saúde. Embora seja possível supor que algumas delas tenham desejado essa gravidez, e que seus parceiros conheciam a sua condição sorológica, e que, ademais, foram tomados todos os cuidados para prevenir a infecção do parceiro ou uma reinfecção, é possível supor também que, apesar do contato reiterado com serviços de saúde, essas meninas não tiveram suas demandas de saúde sexual e reprodutiva plenamente atendidas, e talvez se expuseram ao risco, da gravidez ou reinfecção, inadvertidamente. Ainda na cidade de São Paulo, em 2004 foram notificados 885 casos de DST entre pessoas de 13 e 18 anos. As meninas contribuíram com um número maior de casos que os meninos e, destas meninas, $63,4 \%$ têm até a $8 \underline{a}$ série.

\section{Concluindo}

São múltiplos os caminhos que levam um jovem a ter relações sexuais desprotegidas, e os números que vêm à tona sobre a gravidez, DST ou sobre a infecção pelo HIV sem dúvida são menores do que os números reais.

Os dados apresentados ao longo do texto indicam que a abordagem do sexo seguro entre jovens continua sendo necessária, exigindo esforços de produção de estratégias criativas que façam sentido nos diferentes contextos sócioculturais nos quais os jovens experimentam o sexo 21 .

Os jovens são distintos entre si e lidam com a sua sexualidade de forma diversa. O uso do preservativo é o oposto da espontaneidade que se costuma atribuir ao sexo e à juventude. Assim, o estímulo ao uso do preservativo deve incluir a dimensão do erotismo e da praticidade, não apenas o medo.

Os jovens não se percebem em risco para o HIV. A prevenção sexual seria em função da gravidez, nem sempre indesejada, nem sempre vista como algo cuja prevenção estaria sob responsabilidade também do rapaz.

A gravidez entre os jovens tem múltiplas facetas e nuances, não repercutindo de modo semelhante para todos que têm filhos antes dos 20 anos. No entanto, parte dos jovens que engravidam nessa faixa etária vive em condições sociais, econômicas e culturais semelhantes aos jovens que se infectam pelo HIV. A aproximação entre a prevenção da gravidez e a da infecção pelo HIV continua sendo um desafio a ser enfrentado. 


\section{Resumo}

O aumento da gravidez na adolescência e da vulnerabilidade dos jovens ao HIV tem sido um grave problema. Pretende-se problematizar esta assertiva pela análise dos termos que a estrutura - adolescência, juventude, gravidez na adolescência e vulnerabilidadee pela revisão não exaustiva da literatura referente ao tema. Neste artigo discutem-se as idéias de juventude e adolescência para abordar a sexualidade dos jovens e adolescentes sob a perspectiva das desigualdades entre os diferentes grupos sociais e seu acesso à saúde e aos recursos para prevenção de doenças como HIVI AIDS e à contracepção. São múltiplos os caminhos que

\section{Colaboradores}

D. T. Doreto fez a revisão bibliográfica que dá base ao manuscrito. W. V. Villela elaborou a versão final do texto.

\section{Referências}

1. World Health Organization. Family and reproductive health, women's health and development program. Geneva: World Health Organization; 1997.

2. Kraiczyk J. Construção das representações de ser adolescente e ser jovem e a interface com os direitos sexuais e reprodutivos. São Paulo: ECOS; 2005.

3. Waiselfilsh J. Juventude, violência e cidadania: os jovens de Brasília. São Paulo: Organização das Nações Unidas para a Educação, a Ciência e a Cultura/Cortez Editora; 1998.

4. Instituto Brasileiro de Geografia e Estatística. Censo demográfico 2000. http:/ /www.ibge.gov.br (acessado em 07/Ago/2005).

5. Ministério do Planejamento, Orçamento e Gestão/Instituto de Pesquisa Econômica Aplicada. O estudo de uma nação. http://www.ipea.gov.br (acessado em 09/Jul/2005).

6. Rede Feminista de Saúde. Adolescentes, saúde sexual, saúde reprodutiva. Belo Horizonte: Rede Feminista de Saúde; 2004.

7. Heilborn ML, Aquino EML, Knauth DR. Juventude, sexualidade e reprodução. Cad Saúde Pública $2006 ; 22: 1362-3$

8. Secretaria de Estado da Saúde de São Paulo. Programa Saúde do Adolescente. São Paulo: Secretaria de Estado da Saúde de São Paulo; 2003.

9. Organização das Nações Unidas para a Educação, a Ciência e a Cultura. Juventude e sexualidade. Brasília: Organização das Nações Unidas para a Educação, a Ciência e a Cultura; 2004.

10. Aquino EML, Heilborn ML, Knauth D, Bozon M, Almeida MC, Araújo J, et al. Adolescência e reprodução no Brasil: a heterogeneidade dos perfis sociais. Cad Saúde Pública 2003; 19 Suppl 2:S37788.

11. Gera NF. Gravidez na adolescência: conhecimentos e uso de métodos anticoncepcionais entre adolescentes de baixa renda [Dissertação de Mestrado]. Ribeirão Preto: Faculdade de Medicina de Ribeirão Preto, Universidade de São Paulo; 2004. levam um jovem a ter relações sexuais desprotegidas, $e$ os números que vêm à tona sobre a gravidez, DST ou sobre a infecção pelo HIV sem dúvida são menores do que os números reais. Os dados apresentados ao longo do texto indicam que a abordagem do sexo seguro entre jovens continua sendo necessária, exigindo esforços de produção de estratégias criativas que façam sentido nos diferentes contextos sócio-culturais nos quais os jovens experimentam o sexo.

Gravidez na Adolescência; HIV; Adolescente; Políticas Públicas
12. Takiuti A. Sexualidade e plano de vida do adolescente em São Paulo. Projeto de pesquisa. São Paulo: Secretaria de Estado da Saúde de São Paulo; s.d.

13. Almeida MCC, Aquino EML, Barros AP. School trajectory and teenage pregnancy in three Brazilian state capitals. Cad Saúde Pública 2006; 22:1397409 .

14. Oliveira-Costa MC, Lima LC, Martins Jr. DF, Santos CAST, Araújo FPO, Assis DR. Gravidez na adolescência e a co-responsabilidade paterna: trajetória sócio-demográfica e atitudes com a gestação e a criança. Ciênc Saúde Coletiva 2005; 3 : 719-27.

15. Takiuti A. Gravidez entre adolescentes no Estado de São Paulo. São Paulo: Secretaria de Estado da Saúde de São Paulo; 2003.

16. Cabral C. Contracepção e gravidez na adolescência na perspectiva de jovens pais de uma comunidade favelada do Rio de Janeiro. Cad Saúde Pública 2003; 19 Suppl 2:S283-90.

17. Departamento de Informação e Informática do SUS. Informações em saúde. http://www.saude. gov.br/datasus (acessado em 20/Jan/2006).

18. Ministério da Saúde. Pesquisa: conhecimento, atitude e prática. http://www.aids.gov.br. (acessado em 20/Ago/2005)

19. Ministério da Saúde. Monitor AIDS. http://www. aids.gov.br (acessado em Dez/2005).

20. Secretaria da Saúde do Estado de São Paulo. Boletim Epidemiológico de AIDS no Município de São Paulo 2004; Ano VIII, n. 8.

21. Teixeira AMFB, Knauth DR, Fachel JMG, Leal AF. Adolescentes e uso de preservativos: as escolhas dos jovens de três capitais brasileiras na iniciação e na última relação sexual. Cad Saúde Pública 2006; 22:1385-96.

Recebido em 04/Mai/2006 Aprovado em 27/Jul/2006 